\title{
Recuperação de Estudos ou de Nota: uma proposta metodológica no campo tecnológico, utilizando a matemática como instrumento de pesquisa.
}

\author{
William Geraldo Sallum, CEFET-MG - william@decom.cefetmg.br \\ Adelson de Paula Silva, CEFT-MG - adelson@kosmus.com.br \\ Juliano Schimiguel, UNICSUL - schimiguel@gmail.com
}

\section{Resumo}

Com este trabalho buscou-se avaliar o processo de recuperação de conteúdo através do uso de recursos tecnológicos que suportam o ensino a distância. A proposta passa por um estudo que consiste em levantar e analisar as questões que envolvem o processo de recuperação escolar no ensino médio, tendo como foco de pesquisa a disciplina de matemática. O método para proporcionar a recuperação de conteúdo tomou como referência o uso de objetos de aprendizagem. Estes objetos foram disponibilizados em repositórios, com acesso pela Internet, através de plataformas aplicadas ao ensino a distância. $\mathrm{O}$ acesso a plataforma online foi realizado durante o processo de recuperação dos alunos do $1^{\circ}$ e $2^{\circ}$ anos na disciplina de matemática do CEFET-MG, campus Divinópolis. A pesquisa é de natureza aplicada, possui o caráter inovador dentro de uma abordagem quali-quantitativa, desenvolvendo uma série de etapas com atividades interativas, proporcionando uma pesquisa-ação. Resultados positivos foram apurados junto ao grupo de alunos estudados, gerando índices de aproveitamento muito interessantes, quando comparados aos resultados obtidos no processo de recuperação tradicional, presencial.

Palavras-chave: Recuperação de Estudos, EaD, Matemática, TIC

\begin{abstract}
With this work we aimed to evaluate the process of retrieval of content through the use of technological resources that support distance learning. The proposal involves a study that consists of collecting and analyzing the issues surrounding the recovery process of school in high school, focusing on the research discipline of mathematics. The method for providing content retrieval took as a reference the use of learning objects. These objects were made available in repositories, accessed over the Internet through applied to distance learning platforms. Access the online platform was performed during the recovery process of the students from $1^{\text {st }}$ to $2^{\text {nd }}$ years in the discipline of mathematics of CEFET-MG, Divinopolis Campus. The research is of an applied nature, has the innovative character within a qualitative and quantitative approach, developing a series of steps with interactive activities, providing an action research. Positive results were determined by the group of students studied, generating rates of utilization very interesting when compared to results obtained in the traditional retrieval process, classroom.
\end{abstract}

Keywords: Recovery Studies, e-Learning, mathematics, ICT 


\section{Introdução}

O processo de ensino-aprendizagem sempre foi motivo de grandes, efusivas, e polêmicas discussões, mas também, interessantes estudos (Piaget, 1968; Vygotysky, 1983; Ausubel, 1980, 1982, 2003; Moura, 2005; Pietrocola, 2002; dentre outros).

Dentro de todo o processo de ensino-aprendizagem, a recuperação de estudos é considerada instrumento fundamental para a retomada de conteúdos não apreendidos, com reformulação nos procedimentos e estratégias visando o sucesso efetivo do aluno. Durante muito tempo, a recuperação vem sendo apontada por vários estudiosos (Caldas, 2012; Moura, 2005; Charlot, 2000) como sendo uma das maiores preocupações no campo do aprendizado e o que orbita este processo.

Muito vêm se desenvolvendo, em termos das Tecnologias da Informação e Comunicação (TIC's), no sentido da obtenção de garantias de um ensino-aprendizagem mais eficiente e eficaz. Assim, inúmeros estudos (Piva Jr, 2011; Leite, 2007; Lévy, 1993, 1999; Jonassen, 1998), diversas normas e leis (Brasil, 1996; Minas_Gerais, 1998) vêm sendo construídos no sentido de melhorar a educação e o ensino em todas as suas etapas.

Entretanto, as metodologias aplicadas no processo de recuperação de estudos são tradicionalmente presenciais, manuais e que podem ser semestral/anual, paralela e continuada.

As metodologias de recuperações são assim definidas:

- Recuperação semestral: normalmente, aplicada por um período que varia entre quatorze e vinte dias distribuídos duas vezes no ano. Os alunos integrantes nesse processo têm a oportunidade de tentar recuperar os conteúdos no meio do ano - normalmente efetuados entre sete e dez dias no mês de Julho e entre sete e dez dias no mês de Dezembro, imediatamente antes do recesso e férias escolares, especificamente disponibilizados para essa finalidade;

- Recuperação continuada: ao contrário da semestral, é efetuada paralelamente às atividades letivas, ou seja: ocorre através de atividades compostas de exercícios e avaliações que são, normalmente, efetuadas logo após avaliações finais de cada bimestre.

A ideia original deste estudo consistiu em levantar e analisar as questões que envolvem o processo de recuperação escolar no ensino médio e, a partir da disciplina de matemática, propor metodologias mais eficazes às atualmente utilizadas, empregando, para isso, questionários com alunos e professores de matemática, levantamentos dos resultados de recuperações de estudos de anos anteriores, junto ao Registro Escolar (RE) do Centro Federal de Educação Tecnológica de Minas Gerais - CEFET-MG, instituição de trabalho, utilizada como campo de pesquisa do presente estudo; e execução do processo de recuperação utilizando metodologia de cunho tecnológico.

De um modo geral, verificou-se que o número de trabalhos publicados a respeito de todo o processo que envolve a recuperação de estudos dentro de uma escola é pequeno; principalmente no que diz respeito aos seus resultados (Dutra, 2012; Caldas, 2010) e pela devida importância que o tema inspira.

Dutra e Martins (2012) enfatizam que a recuperação escolar sempre foi motivo de debates "acalorados" entre professores e coordenações pedagógicas, colocando em dúvida a sua validade e reais benefícios enquanto instrumento da (re)construção do conhecimento. Ainda, segundo o autor, tem-se “[...] muitas vezes a impressão de que esse instrumento [recuperação] é usado apenas para reduzir o número de reprovações, amenizando a tensão entre escola, alunos e pais.” 
Podemos, assim, condensar toda esta problemática nas falas de Caldas (2010), através do resumo do seu trabalho de Tese: "Foi consensual entre os participantes da pesquisa a concepção sobre a fragilidade e descrédito da função da recuperação, apontando o esvaziamento do sentido dessa prática pedagógica para todos os seus atores: professores, gestores, pais e alunos.” (Caldas, 2010, P. 7)

Parece haver uma unanimidade ao se considerar que a recuperação de estudos sempre foi vista como uma mera parte agregada do processo de ensino-aprendizagem e que, segundo (Caldas, 2012, P. 210), ela vem representando "quase um estorvo, sem grandes resultados".

Trabalhou-se com a disciplina de matemática, nesta pesquisa, basicamente por dois motivos: por ser uma linguagem universal, pela qual a ciência expressa seu pensamento (Pietrocola, 2002) e pela sua (muitas vezes comentada) “dificuldade de aprendizado" (Silveira, 2011).

A principal questão a ser respondida nesse estudo é: “a utilização da tecnologia como recurso metodológico pode influenciar o resultado do processo de recuperação de estudos na disciplina de matemática do ensino médio em detrimento ao processo tradicionalmente utilizado?”.

A pesquisa entre alunos e professores foi elaborada tomando como instrumento de diálogo, questionários dirigidos aos professores de matemática e aos alunos que já passaram por procedimentos de recuperação de estudos.

Para efetivar a pesquisa, utilizamos dois Ambientes Virtuais de Aprendizagem (AVA's): um pago, denominado Plano Educação ${ }^{1}$ e um gratuito, denominado Moodle ${ }^{2}$. Foi necessária a adoção de dois AVA's porque, até o presente momento, não foi observado um único ambiente que tenha incorporado todas as características necessárias a essa pesquisa:

- Objetos de Aprendizagem (OA's), tais como Vídeo aulas e Apostilas e

- atividades, tais como: exercícios avaliativos, fóruns, chat's e e-mails.

O Moodle, ambiente adotado pelo CEFET-MG e voltado para seu processo de ensino, pesquisa e extensão, foi disponibilizado para essa pesquisa no desenvolvimento das atividades anteriormente relatadas. E, para completar o processo de ensino-aprendizado proposto em tal pesquisa, o ambiente Plano Educação foi também utilizado para o provimento de OA's pertinentes ao conteúdo referenciado nos Parâmetros Curriculares Nacionais - PCN relativos as primeiras séries do ensino médio.

\section{Referencial de Trabalho}

A recuperação de estudos, por si só, no contexto pedagógico, não é um mero processo de ensino-aprendizagem em que docentes e instituições de ensino resolvem pela sua aplicação em condições meramente particulares. Ao contrário, é um instrumento de relevância capital. Prova disso pode ser observada pelas determinações estabelecidas pelas leis e diretrizes promulgadas. Originalmente, a lei maior dirigida à educação nacional: (Brasil, 1996) em seus artigos, 12, 13 e 24 estabelecem determinações que enfocam tal importância e consequente obrigatoriedade.

Dutra (2012) aponta a recuperação “como um instrumento capaz de recuperar também a autoestima, a consciência, ou simplesmente oferecer mais tempo ao aluno para que alcance os objetivos previstos.”

\footnotetext{
${ }^{1}$ http://www.planoeducacao.com.br/

${ }^{2}$ http://moodle.cefetmg.br/course/category.php?id=125
} 
De acordo com Silva (2001), a evolução das TICs, vai para além de possibilitar atividades educacionais à distância no sentido de melhorar a qualidade de ensino, promovendo, assim, a construção do conhecimento de forma interativa e participativa. Pierre Lèvy (Levy, 1993, 1994), em várias de suas obras, aborda sobre a importância da utilização do computador e outros recursos correlatos na aprendizagem sob os auspícios dos recursos cibernéticos.

Dentro dessa perspectiva, infere-se que os professores, as técnicas, as metodologias e as TIC's como softwares educacionais ou Objetos de Aprendizagem (OA's), Ambientes de ensino Aprendizagem (AVA's) e metodologia de Ensino à Distância (EaD) utilizados no ensino, são elementos mediadores importantes nesse processo (Vygotsky, 1987).

Segundo Wiley (2011), os OA's são recursos que permitem aos professores criarem pequenos componentes instrucionais, os quais podem ser reutilizados em diferentes contextos de aprendizagem, auxiliando tanto a modalidade à distância como a presencial. Estes recursos foram desenvolvidos para as várias áreas do saber, inclusive para a Matemática.

\section{Metodologia e Análise}

Como fruto de um trabalho maior, pinçamos breves conteúdos de cada etapa a fim de comunicar aqui o cerne do trabalho. O estudo é de cunho quali-quantitativo onde se utilizou as técnicas de estudo de caso e pesquisa-ação como metodologias da pesquisa. Este documento foi particionado nas etapas: 1- Levantamento dos dados referentes às recuperações efetuadas entre 2007 e 2011; 2- Análise e resultados dos questionários aplicados nos professores; 3- análise e resultados dos questionários aplicados nos alunos; 4- Análise e resultados comparando-se os resultados obtidos pelas fases 1, 2 e 3; 5- Aplicação da recuperação final de 2012, utilizando a metodologia proposta com o uso de TIC's; e 6- resultados finais e considerações.

Inicialmente, foi efetuado um levantamento dos dados referentes às recuperações ocorridas, ano a ano, nas disciplinas de matemática, nos três cursos técnicos: Eletromecânica, Informática e Produção de Modas; em todas as séries, buscando os números de alunos aprovados e reprovados no processo de recuperação de estudos, especificamente do campus de Divinópolis-MG. Os dados aqui obtidos foram levantados na sessão de Registro Escolar (RE) local (campus Divinópolis do CEFETMG) e junto ao Departamento de Recursos em Informática (DRI) do CEFET-MG, em Belo Horizonte.

\section{Levantamentos de dados referentes às recuperações anteriores pelo $\mathrm{RE}$}

Iniciamos a apresentação pelos dados referentes às aprovações e reprovações efetivadas após as recuperações de estudos ocorridas durante os anos de 2007 a 2011, conforme pode ser observado na Tabela 1.

Nos números da Tabela 1 já foram deduzidos os alunos que, tendo apresentado dificuldades de aprendizagem, solicitaram suas transferências para outras escolas com a finalidade de evitar a própria reprovação e/ou jubilamento ${ }^{3}$.

A queda no número de reprovações nos anos de 2008 e 2010 induziu a solicitação de um novo levantamento de todos os dados anteriormente solicitados. A tabela 2 traz os dados de todos os alunos reprovados na disciplina de matemática nos três cursos

3 No CEFET-MG o aluno é jubilado se for reprovado duas vezes numa mesma série (CEFET-MG, p.22. 2011) 
integrados durante o período de 2007 a 2011, tendo os alunos passados pela recuperação ou não.

Tabela 1 - Relação de alunos que fizerem recuperação na disciplina de matemática

\begin{tabular}{|c|c|c|c|c|}
\hline ANO & $\begin{array}{c}\text { MÉDIA de } \\
\text { ALUNOS } \\
\text { INGRESS OS }\end{array}$ & $\begin{array}{c}\text { Aprovados após } \\
\text { Recuperação }\end{array}$ & $\begin{array}{c}\text { Reprovados } \\
\text { após } \\
\text { Recuperação }\end{array}$ & $\begin{array}{c}\text { Total de alunos } \\
\text { em } \\
\text { Recuperação }\end{array}$ \\
\hline $\mathbf{2 0 0 7}$ & 300 & 34 & 25 & 59 \\
\hline $\mathbf{2 0 0 8}$ & 300 & 23 & 15 & 38 \\
\hline $\mathbf{2 0 0 9}$ & 300 & 17 & 27 & 44 \\
\hline $\mathbf{2 0 1 0}$ & 300 & 8 & 8 & 16 \\
\hline $\mathbf{2 0 1 1}$ & 300 & 2 & 16 & 18 \\
\hline & $\mathbf{1 5 0 0}$ & $\mathbf{8 4}$ & $\mathbf{9 1}$ & $\mathbf{1 7 5}$ \\
\hline
\end{tabular}

Fonte: Registro Escolar - CEFET-MG - Campus Divinópolis

Tabela 2 - Relação de alunos reprovados em matemática no período de 2007 a 2011.

\begin{tabular}{|c|c|c|c|}
\hline \multicolumn{2}{|c|}{$\begin{array}{l}\text { Campus Divinópolis } \\
\text { Candar }\end{array}$} & \multicolumn{2}{|c|}{$\begin{array}{c}\text { Qtd total de alunos } \\
\text { REPROVADOS dentro e fora } \\
\text { da Recuperação }\end{array}$} \\
\hline \multirow[t]{2}{*}{ ANO } & CURSOS & Por curso & Por ano \\
\hline & Eletromecânica & 9 & \multirow{3}{*}{38} \\
\hline \multirow{2}{*}{2007} & PGTI/Informática & 19 & \\
\hline & Vestuário/Prod.Modas & 10 & \\
\hline \multirow{3}{*}{2008} & Eletromecânica & 4 & \multirow{3}{*}{23} \\
\hline & PGTI/Informática & 9 & \\
\hline & Vestuário/Prod.Modas & 10 & \\
\hline \multirow{3}{*}{2009} & Eletromecânica & 5 & \multirow{3}{*}{27} \\
\hline & PGTI/Informática & 9 & \\
\hline & Vestuário/Prod.Modas & 13 & \\
\hline \multirow{3}{*}{2010} & Eletromecânica & 1 & \multirow{3}{*}{12} \\
\hline & PGTI/Informática & 11 & \\
\hline & Vestuário/Prod.Modas & 0 & \\
\hline \multirow{3}{*}{2011} & Eletromecânica & 5 & \multirow{3}{*}{16} \\
\hline & PGTI/Informática & 3 & \\
\hline & Vestuário/Prod.Modas & 8 & \\
\hline & & Total & 116 \\
\hline
\end{tabular}

Fonte: Departamento de Recursos em Informática - CEFET-MG

Comparando o total da Tabela 1 (coluna "Reprovados em Recuperação por Ano") e Tabela 2, observa-se que o total de alunos reprovados dentro e fora de recuperações foi de 91, contra 116 respectivamente, demonstrando coerência na proporcionalidade entre as duas amostras. Traçou-se, então, o Gráfico 1 mostrando tal relação através da linha que se apresenta tracejada. Observa-se, a partir daí, que as inclinações produzidas por esta linha são semelhantes e proporcionais a linha que representa a quantidade de alunos “Reprovados após Recuperação”, induzindo a verificação da relação de coerência entre as mesmas.

Mesmo constatando a assertividade dos dados extraídos e a coerência entre o grupo maior de dados extraídos e o subgrupo correspondente, a flutuação entre períodos era evidente e sem aparente explicação. 


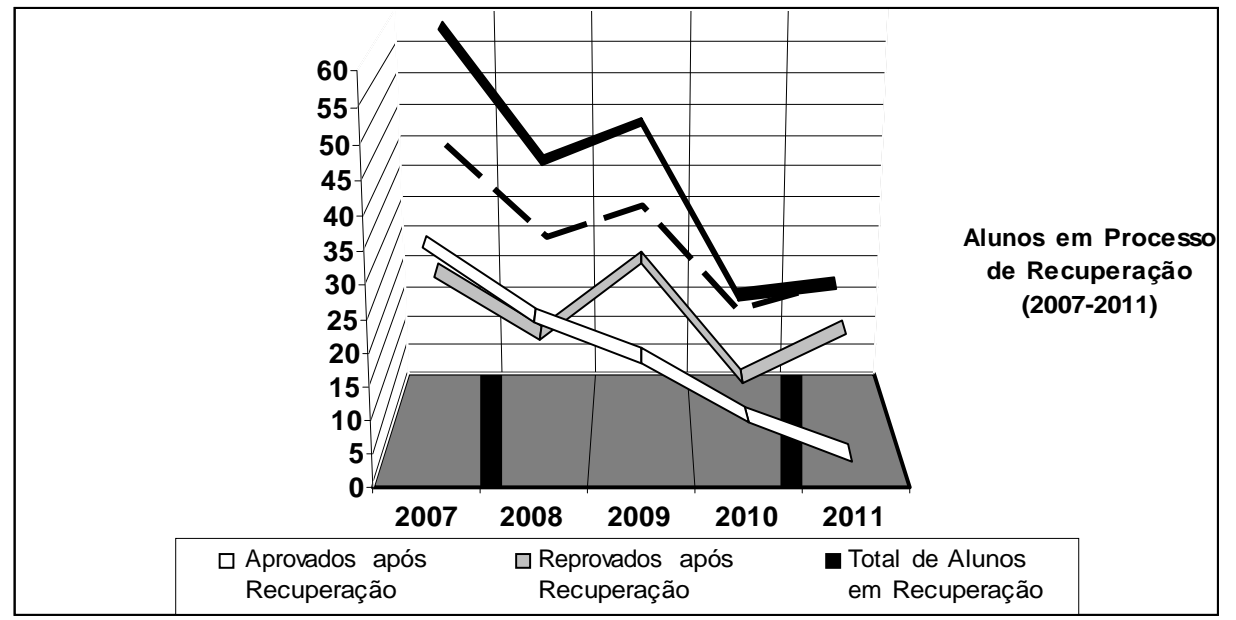

Gráfico 1 - Gráfico comparativo entre alunos em recuperação e total de alunos reprovados indistintamente à recuperação na disciplina de matemática.

Então, outra questão surgiu: poderia ter ocorrido algum tipo de evasão significativa anômala que pudesse explicar as quedas bruscas no número de reprovação nos anos de 2008 e 2010 ?

Verificou-se que nos anos de 2007, 2008, 2009 e 2011 a metodologia empregada era de Recuperação Semestral, ou seja, recuperação que ocorre duas vezes ao ano. Porém, a recuperação do ano de 2010 utilizou a metodologia de Recuperação Continuada, ou seja: recuperação executada durante os quatro bimestres, indicando o que motivou a queda no número de reprovações na recuperação de 2010 em relação aos outros anos.

Apesar dos dados levantados sugerirem alguma resposta às oscilações nos números de reprovações em recuperações, viu-se a necessidade de "conversar" com os professores e alunos sobre o tema "Recuperação de Estudos na Disciplina de Matemática". Dois questionários foram submetidos aos professores e alunos, respectivamente.

Comparativo entre os resultados dos questionários e o levantamento de dados

Confrontando os dados do Registro Escolar com os dos questionários efetuados com os alunos, verificou-se que ambos se complementam e se confirmam, apresentando índices muito próximos. Desde ponto em diante, foi possível fazer uma breve discussão entre os questionários dos alunos e dos professores.

Quanto a questão sobre o percentual de alunos que foram aprovados por "força da nota”, há uma clara indefinição: $6 \%$ dos alunos alegam que foram aprovados, não pelo que sabiam do conteúdo, mas apenas pela recuperação das notas necessárias . Por outro lado, os professores acreditam que 38\% dos alunos que se submeteram aos processos de recuperação e foram aprovados, o foram pela mesma "força da nota". O distanciamento entre tais percentuais pode ter explicação no fato de que, ao professor sobrevalorizar as atividades dos alunos, estes mesmos alunos, na maioria das vezes, ficam sem saber sobre esse procedimento de "ajuda".

Verificou-se uma grande coesão entre as respostas dos docentes e a dos discentes aos questionamentos que indagaram sobre as dificuldades do aprendizado da disciplina de matemática. Ambos atribuem grande parte dos fracassos desse processo aos extensos conteúdos a serem resgatados e, por conseguinte, ao pouco tempo destinado à recuperação de estudos. 


\section{Aplicação da pesquisa-ação com uso do EaD}

Nesta fase da pesquisa, adotamos o uso de Objetos de Aprendizagem (OA's) através das plataformas: Plano de Educação e Moodle, ambos na modalidade de EaD.

Inicialmente, conversou-se com os professores de matemática no sentido de instruí-los e orientá-los na condução da pesquisa e no papel que os mesmos representariam dentro do projeto.

Em seguida, foi solicitado aos professores, que apurassem, mediante aproveitamento final, todos os alunos que entrariam em processo de recuperação de estudos. Estes alunos possuíam avaliação entre 40 e 59 pontos. Após reuni-los, foi palestrado aos mesmos e na presença de seus respectivos professores a respeito dos preceitos e da importância da pesquisa científica a qual eles participariam. Foi instruído a todos os presentes sobre o funcionamento da nova metodologia e sobre os instrumentos tecnológicos que deveriam utilizar durante todo o processo da recuperação. Ao final, foi entregue aos alunos (aos menores de idade) o documento que, uma vez assinado pelos respectivos responsáveis, autorizaria aos mesmos participar de tal processo.

De um lado, possuíamos os dados oriundos da pesquisa preliminar, construída entre professores, alunos e dados de recuperações de anos passados. De outro, a possibilidade de verificar a hipótese.

Nesta fase, o objetivo consistiu em verificar a eficiência do uso das TIC's no processo de recuperação escolar, mediante o confronto dos dados produzidos aqui e os dados anteriormente levantados.

Após várias pesquisas, percebeu-se a existência de um ambiente que continha vários elementos necessários para a conclusão dos nossos objetivos no estudo. Esse ambiente, o Plano Educação, continha OA's tais como vídeo aulas e apostilas, mas não possuía atividades de interação, tais como fóruns e chat's para troca de informações entre os alunos, professores e elementos de avaliação. Assim, tivemos que criar no sistema Moodle do CEFET-MG, um espaço específico da pesquisa, onde foram introduzidas as atividades inexistentes ao ambiente Plano Educação.

No AVA Plano Educação, os alunos, após receberem um cartão de acesso individual, instruíram-se através de inúmeros vídeos educacionais e livros correlacionados. Através da plataforma de ensino-aprendizagem Moodle, os alunos em recuperação puderam ter acesso às várias atividades contendo questionários que os orientavam e os auxiliavam na disciplina de matemática. Essa plataforma foi aplicada durante a recuperação dos alunos do $1^{\circ}$ e $2^{\circ}$ anos na disciplina de matemática.

Na plataforma Moodle, foram construídas avaliações para todas as séries do ensino médio em conformidade com os Parâmetros Curriculares Nacionais - PCN. Nesta plataforma foram construídas 1742 questões distribuídas da seguinte forma: 520 questões na $1^{\mathrm{a}}$ série, 936 na $2^{\mathrm{a}}$ série e 286 na $3^{\mathrm{a}}$. Dessas, os professores selecionaram 45 questões que julgaram pertinentes aos estudos perdidos. Na medida em que os alunos iam fazendo as questões, os professores faziam as devidas correções e avaliações, com auxilio automatizado do ambiente.

O processo de recuperação final se deu entre os dias 08 e 12 de abril de 2013 e produziu: 6 fóruns de discussão e de dúvidas; 17 tópicos de mensagens e, desses, 52 comentários. Foram assistidos 398 vídeos na plataforma Plano Educação.

Precisamente no dia 12 de abril de 2013, os professores aplicaram uma prova final escrita e presencial para todos os alunos que concluíram o processo de recuperação de estudos. Ao final do processo de recuperação de estudos, os professores coletaram todos os dados pertinentes, organizando as notas, avaliações e participações dos alunos em uma planilha. 
Ao final da pesquisa, foram verificados os seguintes resultados: alunos em recuperação: 32; alunos desistentes: 3; alunos concluintes: 29; alunos aprovados: 25; e alunos reprovados: 4.

\section{Conclusões e considerações finais}

Constatou-se, nesse estudo, que existem muitas queixas acerca do pouco tempo e da grande quantidade de conteúdos dirigidos ao processo. Além disso, escolheu-se como instrumento de pesquisa uma disciplina que, diante das respostas aos questionamentos, é tida como de maior dificuldade dentre todas as outras. Mas, esta escolha não foi meramente uma opção. Foi percebido que, trabalhar com uma disciplina de difícil aprendizado, poderia potencializar o valor desse estudo.

O presente estudo desenvolveu-se, basicamente, em duas fases: um estudo preliminar, onde deveria ser levantados dados - até então inexistentes - justificantes da presente pesquisa e a própria pesquisa em si. Em outras palavras, foi necessário o desenvolvimento inicial de um estudo envolvendo coleta de dados digitais e questionários efetuados com professores e alunos, que pudessem servir de informação a respeito da realidade do processo de recuperação de estudos para, a partir daí, aplicar a metodologia proposta e verificar sua eficácia.

Buscando os dados produzidos pelos estudos preliminares, constatamos num primeiro momento, dois pontos de vistas: inconstância do equilíbrio das aprovações/reprovações no processo de recuperação de estudos e índice de aprovação insatisfatório dentro da recuperação de estudos.

Aplicando-se a metodologia de EaD, com uso de OA's controlados por AVA's e orientados pelo professor, constatamos que o índice de aprovação dentro do processo de recuperação, aplicado em 2012, teve um aumento substancial. Ocorreram 86,2\% de aprovações contra o melhor resultado em 2008 que ficou em 48\%.

O presente estudo comprovou a hipótese de que a utilização da tecnologia como recurso metodológico influenciou no resultado do processo de recuperação de estudos na disciplina de matemática do ensino médio - se comparado ao processo tradicionalmente utilizado -; e aqui o resultado observado foi positivo, sob o ponto de vista do aproveitamento e respectivas aprovações.

As diferentes modalidades de recuperação aplicadas tiveram influência nos respectivos resultados. A partir da pesquisa preliminar, acreditamos que a modalidade de recuperação continuada se mostra mais efetiva. Entretanto e sabendo-se da inviabilidade de se praticar tal modalidade, de forma paralela, não cabe nos horários letivos destinados ao ensino, dentro da instituição.

Nesse sentido, acreditamos que a utilização da EaD no processo de recuperação pode ser uma solução atemporal, espacialmente viável e efetiva.

Importante mencionar que outros fatores, não pertencentes ao foco desse estudo, podem ter colaborado no resultado produzido. Dentre estes fatores, sugerimos consultas a algumas referências, tais como a teoria do reforço (método Keller) em: "Sistema de Instrução Personalizada” (Moreira, 1973), além de D’Ambrosio (1989) e Castro (2004).

\section{Referências}

AUSUBEL, D. P.; NOVAK, J. D. e HANESIAN, H. Psicologia Educacional. Rio de Janeiro: Editora Interamericana, $2{ }^{\text {a }}$ Ed.,1980.

BRASIL. LDB - Lei de Diretrizes e Bases da Educação Nacional de 20 de Dezembro de 1996: Lei $\mathrm{n}^{0}$ 9.394, de 20 de dezembro de 1996, que estabelece as diretrizes e 
bases da educação nacional. $8^{\circ}$ Ed. - Brasília: Câmara dos Deputados, Edições Câmara, 2013.

CALDAS, Roseli Fernandes Lins. Recuperação escolar: discurso oficial e cotidiano educacional - um estudo a partir da Psicologia Escolar. 2010. 264 f. Tese (Doutorado) Instituto de Psicologia. Universidade de São Paulo, 2010.

CASTRO, Juliana Facanali. Um estudo sobre a própria prática em um contexto de aulas investigativas de Matemática. 2004. 197 f. Dissertação (Mestrado em Educação Matemática). Universidade Estadual de Campinas, UNICAMP, Brasil. 2004. Disponível em:

<http://www.educadores.diaadia.pr.gov.br/arquivos/File/2010/artigos_teses/2011/mate matica/maio/dissertacao_juliana_facanali_castro.pdf > . Acesso em: 26 jun. 2014.

CHARLOT, B. Da Relação com o Saber: elementos para uma teoria. Tradução Bruno Magne. Porto Alegre: artes Médicas Sul, 2000.

D’AMBROSIO, Beatriz S. Como Ensinar Matemática Hoje? 1989. Disponível em: $<$ http://educadores.diaadia.pr.gov.br/arquivos/File/2010/artigos_teses/MATEMATICA/Arti go_Beatriz.pdf>. Acesso em: 27 dez. 2013.

DUTRA, Glênon; MARTINS, Maria Inês. Avaliação e Políticas Públicas em Educação. Ensaio: aval.pol.públ.Educ. vol.20 no.74 Rio de Janeiro Jan./Mar. 2012. Disponível em: $\quad<$ http://www.scielo.br/scielo.php?pid=S010440362012000100008\&script=sci_arttext>. Acesso em: 01 ago. 2012.

JONASSEN, David. O Uso das Novas Tecnologias na Educação a Distância e a Aprendizagem Construtivista.- Em Aberto sobre Educação a Distância INEP, MEC, v.16 n.70, abr/jun 1998.

LEITE, M. D. Design da interação de interfaces educativas para o ensino de matemática para crianças e jovens surdos. Dissertação (Mestrado em Ciência da Computação) - Centro de Informática, UFPE, 157 p. 2007.

LÈVY, Pierre. As tecnologias da Inteligência: o futuro do pensamento na era da informática. Rio de Janeiro: ed. 34, 1993. 1999.

Pierre. Cibercultura. Tradução de Carlos Irineu da Costa. São Paulo: ed. 34,

MINAS_GERAIS (Estado). Conselho Estadual de Educação de Minas Gerais. Parecer 1158, de 11 de dezembro de 1998. Dispõe sobre a operacionalização da educação básica nos termos da Lei 9394/1996. Belo Horizonte: CEE/MG, 1998. Disponível em: <http://www.cee.mg.gov.br/parecercee.htm>. Acesso em: 12 nov. 2010.

MOURA, Solange Altoé de. Projeto de recuperação paralela da Matemática básica através da utilização de objetos de aprendizagem multimídia. Rio de Janeiro, 2005. 212 p. Dissertação (Mestrado em Informática) - Universidade Federal do Rio de Janeiro, Instituto de Matemática, Núcleo de Computação Eletrônica, 2005.

MOREIRA, M. A. Observações e comentários sobre dois sistemas de ensino individualizado. Revista Brasileira de Física, 3, 167-71, 1973.

PIETROCOLA, Mauríci. A Matemática como Estruturante do Conhecimento Físico, Cad. Cat. Ens. Fís., v.19, n.1: p.89-109, ago. 2002.

PIVA Jr., Dilermando; PUPO, Ricardo; GAMEZ, Luciano; OLIVEIRA, Saullo. EaD na Prática: planejamento, métodos e ambientes de educação online. Rio de Janeiro: Elsevier, 2011. 
SILVA, Roberto Wagner Andrade da Silva. Educação a Distância em Ambientes de Aprendizagem Matemática Auxiliada pela Realidade Virtual. 2001, 123p. Dissertação (mestrado em Engenharia de Produção) - Programa de Pós -Graduação em Engenharia de Produção, Florianópolis:UFSC, 2001.

SILVEIRA, Marisa Rosâni Abreu da, A Dificuldade da Matemática no Dizer do Aluno: ressonâncias de sentido de um discurso. Revista Educação e Realidade. v. 36, n. 3. p. 761-779, Porto Alegre. set./dez. 2011. Disponível em: <http://www.ufrgs.br/edu_realidade>. Acesso em: 02 jan. 2012.

WILEY, D. The instructional use of learning objects. 2002. Disponível em: <http://www.reusability.org/read>. Acesso em: 21 nov. 2010.

VYGOTSKY, Lev. Pensamento e linguagem. SP: Martins Fontes, 1987. 